\title{
The "perfect" hypospadias repair: Are we there yet?
}

\author{
Armando J. Lorenzo, MD, FRCSC
}

See related article on page 110

I n this issue of CUAJ, Almodhen and colleagues ${ }^{1}$ present a somewhat reassuring addition to the large literature on the tubularized incised plate (TIP) repair and its variations. A case is made for attempting to "recreate" the normal penile anatomy by using the Y-to-I spongioplasty wrap as described by Yerkes and colleagues. ${ }^{2}$ By doing so, a good short-term outcome can be achieved without insertion of a urethral stent, as indicated by Almodhen and colleagues. Following a study design that is common to many other papers on hypospadias repair, a relatively small and select group of children underwent the described procedure. In the absence of a control group, the lack of major complications coupled with an "excellent" cosmetic result are given as compelling reasons to adopt the technique.

Although it is commendable to accrue such experience in an organized fashion and present it for others to review, I find it worrisome that we as pediatric urologists and surgeons do not seem to be able to move on and fully embrace study designs that generate levels of evidence higher than case series or retrospective reviews. To state the obvious, caution must be exercised when conclusions are reached based on limited data. The reported children were selected for TIP repair, with an unknown number excluded on the basis of criteria presented in the methods section. Can we generalize the presented data to patients seen in our everyday practice? At which point do we consider a penis too short, the curvature too severe or the urethral plate too "dysplastic" to go on to an alternative technique for repair? Furthermore, it is distressing that outcome evaluations remain not only subjective, but also fairly limited in follow-up. Although a frequently uttered, and to a point relatively meaningless, statement, a good cosmetic and functional result is difficult to measure. With no standardized criteria and the lack of the benefit of an independent observer, it can be a potentially deceptive outcome measure when determined by the surgeon's personal impression or what's on record in the patient's chart. One can probably think of many examples of the potential biases incurred by such reporting; the disparities between physicianrecorded and actual urinary leakage problems after anti-incontinence procedures in adult women come to mind as a situation not foreign to our specialty.

Is performing a spongioplasty the key ingredient to reaching the presented favourable outcome? Certainly, few postoperative problems were encountered over a follow-up period that reached up to 15 months. However, the reader may remain skeptical, as many hypospadias repairs are left unstented after a TIP repair, not including the described spongioplasty, with seemingly good results. Dartos flap coverage may be enough to waterproof the repair, limit the formation of urethro-cutaneous fistulae and support the neourethra. Can we state for a fact that the Y-to-I spongioplasty is facilitating catheterization when such a small number of children required such intervention in the postoperative period? A control group is sorely needed to reach a strong conclusion. However, I must admit that I find the concept attractive, as performing the spongiosum wrap is unlikely to increase complications and makes anatomical sense to carry out as part of the reconstruction.

Anyone who remembers the initial optimism for previous techniques for hypospadias repair would caution us from embracing any new procedure (or variation thereof), pointing out the potential for unforeseen complications and problems in the long run. Let us also remember that an important role of the penis - sexual function - will not be fully explored by most patients for many years after the initial procedure. Although it seems evident, we must always remind ourselves that the results of these interventions will have consequences that the child will have to live with for decades to come. Can we assume that no news is good news and see patients "only when necessary" after the 6-month evaluation (as is the case in the present series)? Admittedly, it is difficult to follow patients for a long time, and it is even harder to predict who will have complications that will merit closer follow-up. However, as stated by Hoag and colleagues in a recent CUAJ article, "long-term outcomes data are critical to an honest account of success rates for hypospadias surgery." 3 Patients who present for second, third, fourth 
(and so on) "redo" procedures, as well as the socalled hypospadias "cripples," are sad and constant reminders of this very important lesson. To echo the words of Dr. Michael Leonard on "The importance of follow-up," an enlightening accompanying commentary that followed Hoag and colleagues' manuscript, "this is the Achilles' heel of our specialty."

The onus is on all of us. To be innovative is key, but with a strong commitment to well-designed prospective studies, aiming at measurable - and relevant - outcomes, with plans for long-term monitoring (and reporting).

We are certainly getting closer, but there's still a long way to go ...
From the University of Toronto, Hospital for Sick Children, Toronto, Ont.

Competing interests: None declared.

\section{References}

1. Almodhen F, Alzahrani A, Jednak R, et al. Nonstented tubularized incised plate urethroplasty with Y-to-I spongioplasty in non-toilet trained children. CUAJ 2008;2:1 10-4.

2. Yerkes EB, Adams MC, Miller DA, et al. Y-to-I wrap: use of the distal spongiosum for hypospadias repair. J Urol 2000;163:1536-8; discussion 1538-9.

3. Hoag CC, Gotto GT, Morrison KB, et al. Long-term functional outcome and satisfaction of patients with hypospadias repaired in childhood. CUAJ 2008;2:23-31.

4. Leonard MP. The importance of follow-up. CUAJ 2008;2:32.

Correspondence: Dr. Armando J. Lorenzo, Hospital for Sick Children, 555 University Ave., Rm. M299 Toronto ON M5G 1X8; armando.lorenzo@sickkids.ca
We accept events for the Calendar section. You may send them to us in the following ways:

\section{Email \\ journal@cua.org}

\section{Fax}

514 875-0205
Mail
$\because \because \ddot{A}$
1155 University Ave.,
Suite 1155
Montréal, QC H3B 3A7

\section{Advances in Female Pelvic Medicine and Reconstructive Pelvic Surgery}

July 10-12, 2008

The Sutton Place Hotel, Toronto, ON

Medical course director: Dr. Harold Drutz

Guest faculty: Dr. Roger Dmochowski, Dr. G. Willy Davila and

Dr. Fred M. Howard

For more information please contact:

Elizabeth Gan

CME - Department of Obstetrics \& Gynaecology

Mount Sinai Hospital / University of Toronto

600 University Ave., Rm. 1255

Toronto ON M5G 1 X5

Phone: 416 586-4800 x2489

Fax: 416 586-5958

Email: egan@mtsinai.on.ca

\section{Robotic Prostatectomy Expert Panel-Review Course}

\section{June 27-28, 2008}

Chicago, IL

Contact: Dr. Kevin C. Zorn

Email: kzorn@surgery.bsd.uchicago.edu

Website: http://RLRPcourse.uchicago.edu 